\title{
Calcium chloride priming increases chilling tolerance in Salvia miltiorrhiza Bunge
}

\author{
Lu Gao ${ }^{1}$ and Min $\operatorname{Yan}^{1 *}$ \\ ${ }^{1}$ Qingdao Agricultural University, College of Agronomy, 266109 Qingdao, China. \\ *Corresponding author (yanmin75@163.com).
}

Received: 25 September 2019; Accepted: 20 December 2019; doi:10.4067/S0718-58392020000200219

\begin{abstract}
Chilling stress inhibits germination and early seedling growth of Salvia miltiorrhiza Bunge. The present study was carried out to investigate the effects of osmopriming with $\mathrm{CaCl}_{2}$ on the germination and early seedling growth of S. miltiorrhiza under chilling stress $\left(10^{\circ} \mathrm{C}\right)$. Seeds were soaked in different concentrations of $\mathrm{CaCl}_{2}$ solutions $(0,50,100$, and 150 $\mathrm{mM}$ ) at $20^{\circ} \mathrm{C}$ for $24 \mathrm{~h}$ in darkness, rinsed, and air-dried. The effects of seed priming were evaluated on germination and survival during subsequent exposure to chilling stress $\left(10^{\circ} \mathrm{C}\right)$ for $14 \mathrm{~d}$. An unprimed control treatment was sown under optimal temperatures $\left(25^{\circ} \mathrm{C}\right)$. Results indicated that germination percentage, germination potential, and seedling vigor index of unprimed seeds decreased from $69.2 \%, 12.4$, and 0.092 to $28 \%, 3.6$, and 0.022 , respectively, when subjected to chilling stress. Higher malondialdehyde (MDA) content and lower chlorophyll contents (including total chlorophyll, chlorophyll $a$, and chlorophyll $b$ ) were detected in S. miltiorrhiza seedlings. Osmopriming with 100 and $150 \mathrm{mM} \mathrm{CaCl}_{2}$ effectively lessened the negative effects of chilling stress. Germination percentage, germination potential, and seedling vigor index of primed seeds reached $42 \%$ and 48\%, 6.36 and 8.78, and 0.037 and 0.047, respectively. Meanwhile, $\mathrm{CaCl}_{2}$ priming significantly triggered superoxide dismutase, peroxidase, and catalase antioxidant enzyme activity, enhanced the accumulation of osmoregulation substances (soluble protein, accumulation sugars, and proline), increased the photosynthetic pigment content (total chlorophyll, chlorophyll $a$, chlorophyll $b$, and carotenoids), and decreased the MDA content. The most effective concentration of $\mathrm{CaCl}_{2}$ priming was $150 \mathrm{mM}$.
\end{abstract}

Key words: Calcium chloride, chilling stress, Salvia miltiorrhiza, seed priming.

\section{INTRODUCTION}

Salvia miltiorrhiza Bunge (family Lamiaceae) is a well-known economical plant used as a drug. Its dried roots, called danshen or tanshen in China and Chinese sage or red sage root in the West, are widely used to treat cardiovascular/ cerebrovascular diseases and various symptoms of inflammation (Hu et al., 2015).

To date, commercial danshen herb mainly relies on the cultivated resource. In most planting areas, S. miltiorrhiza is mainly multiplied by seeds (Chen et al., 2018). Therefore, obtaining fast and orderly seedlings is crucial for high yields. Germination and early seedling growth are critical stages of plant development and are vulnerable to various stress conditions (Bewley et al., 2013). Temperature is a crucial climatic factor that influences seed germination, and each species has a particular set of requirements (Bewley et al., 2013).

The optimum temperature range for S. miltiorrhiza seed germination is between 20 and $25^{\circ} \mathrm{C}$ (He et al., 2014). Salvia miltiorrhiza seeds were sown in early spring, and the temperature often changed dramatically. When the temperature dropped to between $0{ }^{\circ} \mathrm{C}$ and approximately $15{ }^{\circ} \mathrm{C}$, S. miltiorrhiza suffered chilling injury, and this resulted in poor stand establishment. The germination of $S$. miltiorrhiza seed decreases at temperatures below $10^{\circ} \mathrm{C}$ and germination is prevented at temperatures less than $5{ }^{\circ} \mathrm{C}$ (He et al., 2014). Therefore, it is necessary to adopt new techniques to promote S. miltiorrhiza seed germination under chilling stress. 
A large number of reports have demonstrated that seed priming is effective in promoting germination and early seedling growth in many crops under optimal and stress conditions (Li et al., 2017). During priming, seeds are immersed in water or osmotic solutions in such a way that the pre-germination metabolic activities starts; however, radicle protrusion is prevented, followed by the seeds drying to original moisture levels (Paparella et al., 2015). The effect of seed priming on germination varies with the species, chemicals, rates, and duration. Various chemicals with different characteristics have been used as priming agents. These chemicals include hormones, organic solutes, polyethylene glycol, inorganic salts, and natural source extracts (Afzal et al., 2012).

Calcium is an essential nutrient and plays vital structural and signaling roles in plants (Tang and Luan, 2017). It is suggested that $\mathrm{Ca}$ modulates plant responses to abiotic stresses as a stress sensor and transducer (Dodd et al., 2010). Sebastiani et al. (1999) found that a cytosolic Ca concentration in tomato protoplasts increased under chilling stress. Previous studies have indicated that osmopriming with $\mathrm{CaCl}_{2}$ significantly improved grain, straw yield, and harvest index of late sown wheat under chilling stress (Farooq et al., 2008b) and improved the performance of hybrid maize under both optimal and stress conditions (Farooq et al., 2008a).

Although the effects of $\mathrm{CaCl}_{2}$ priming on several crops have been investigated, no reports are available for the medicinal plant S. miltiorrhiza. Therefore, the present study was conducted to evaluate the effects of $\mathrm{CaCl}_{2} \mathrm{priming}$ on the germination of Salvia miltiorrhiza under chilling stress $\left(10^{\circ} \mathrm{C}\right)$ and explain the physiological and biochemical mechanism of priming-induced chilling tolerance in S. miltiorrhiza.

\section{MATERIALS AND METHODS}

Chinese sage (Salvia miltiorrhiza Bunge) 'Sativa' seeds were collected from the Binzhou region, Shandong Province, in June 2019 and preserved at $4{ }^{\circ} \mathrm{C}$ in the Seed Science and Technology Lab of Qingdao Agricultural University until the start of the experiment on 10 July 2019. Seeds were immersed in aerated distilled water (hydropriming) or in different concentrations of $\mathrm{CaCl}_{2}$ solution $(50,100$, and $150 \mathrm{mM})$ at $20^{\circ} \mathrm{C}$ for $24 \mathrm{~h}$ in darkness. After priming, seeds were rinsed with distilled water and air-dried on clean filter paper to the original moisture content (5\%) at $20^{\circ} \mathrm{C}$ for $48 \mathrm{~h}$.

\section{Germination tests}

Four hundred seeds (100 seeds per replicate) from each treatment, including primed and unprimed (non-immersion treatment), were germinated in Petri dishes containing two layers of filter paper moistened with distilled water; seeds were germinated at chilling stress $\left(10^{\circ} \mathrm{C}\right.$ ) with $24 \mathrm{~h}$ light (3000 lux, provided by cool white fluorescent tubes), which increased the germination of S. miltiorrhiza (He et al., 2014). One set of unprimed seeds was germinated at $25^{\circ} \mathrm{C}$ (optimal temperature, control). Seeds were considered to have germinated when the radicle protruded through the seed coat. The number of germinated seeds was recorded daily until day 14 . The germination potential was calculated as $\Sigma(G n / T n)$ where $G n$ is the number of germinated seeds on day $n$ and $T n$ is the number of days from the start of the test. The seedling vigor index was calculated by multiplying the germination potential by seedling fresh weight. The 14-d-old seedlings were immediately used for biochemical analyses (Yan, 2015).

\section{Antioxidant enzymes, lipid peroxidation, and soluble protein}

Salvia miltiorrhiza seedlings $(0.5 \mathrm{~g})$ were ground to a powder with liquid nitrogen and homogenized with ice-cold $50 \mathrm{mM}$ potassium phosphate buffer ( $\mathrm{pH} 7.0)$ containing $2 \mathrm{mM} \mathrm{Na}$-EDTA and $1 \%(\mathrm{w} / \mathrm{v})$ polyvinylpyrrolidone. The homogenates were centrifuged at $14000 \mathrm{~g}$ at $4{ }^{\circ} \mathrm{C}$ for $15 \mathrm{~min}$ and the supernatants were used to determine antioxidant enzyme activity, malondialdehyde (MDA) content, and soluble protein. Catalase (CAT) activity was measured according to the method by Aebi (1974). Peroxidase (POD) activity was determined according to Chance and Maehly (1955). Superoxide dismutase (SOD) activity was measured by the nitroblue tetrazolium method described by Dhindsa et al. (1981). Lipid peroxidation was determined by measuring MDA concentrations as described by Heath and Packer (1968). Soluble protein content was determined according to the method by Bradford (1976).

\section{Proline, soluble sugars, and photosynthetic pigments}

Proline content in seedlings was assayed according to Bates et al. (1973). Total soluble sugar content was determined by the anthrone method (Irigoyen et al., 1992). 
Leaf tissues $(0.5 \mathrm{~g} \mathrm{FW})$ were ground to a powder with liquid nitrogen and $5 \mathrm{~mL} 80 \%$ acetone was added. After vigorous vortexing at $4{ }^{\circ} \mathrm{C}$ for $1 \mathrm{~h}$ in darkness, the mixture was filtered and the volume adjusted to $10 \mathrm{~mL}$ with cold acetone. Extract absorbance was measured at 663,645 , and $470 \mathrm{~nm}$. Pigment concentrations were calculated according to the equations by Lichtenthaler (1987).

\section{Statistical analysis}

All experiments were performed using a completely randomized design. The ANOVA was used to compare priming treatment effects, and significant differences between means were confirmed using Duncan's test $(P \leq 0.05)$. Germination percentage data were arcsine transformed before statistical analysis. All statistical analyses were performed with SPSS Stats 19.0 for Windows (IBM, Armonk, New York, USA).

\section{RESULTS AND DISCUSSION}

\section{Seed priming enhanced germination of Salvia miltiorrhiza under chilling stress}

Germinating seeds of many species are highly susceptible to chilling stress (Bewley et al., 2013). A low temperature at sowing usually results in poor seed germination and seedling establishment (Bewley et al., 2013). The present study indicated that a low temperature played a significant inhibitory effect on seed germination and early establishment of $S$. miltiorrhiza (Figures 1A-1C). Compared with the optimal condition, seed germination was inhibited under chilling stress $\left(10^{\circ} \mathrm{C}\right)$ and germination traits (germination percentage, germination potential, and seedling vigor index) significantly decreased (Figures 1A-1C); this agrees with a previous study (He et al., 2014).

The $\mathrm{CaCl}_{2}$ priming improved seed germination and early seedling growth of S. miltiorrhiza under a low temperature. Seed priming with 100 and $150 \mathrm{mM} \mathrm{CaCl} 2$ significantly increased the germination percentage (Figure $1 \mathrm{~A}$ ) and $\mathrm{CaCl}_{2}$ priming $(50,100$, and $150 \mathrm{mM})$ significantly increased the germination potential under chilling stress (Figure 1B). Seed priming with $150 \mathrm{mM} \mathrm{CaCl}_{2}$ significantly increased the seedling vigor index (Figure 1C) and showed the highest

Figure 1. Influence of $\mathrm{CaCl}_{2}$ priming on germination percentage (A), germination potential (B), and seedling vigor index (C) of Salvia miltiorrhiza under chilling stress.

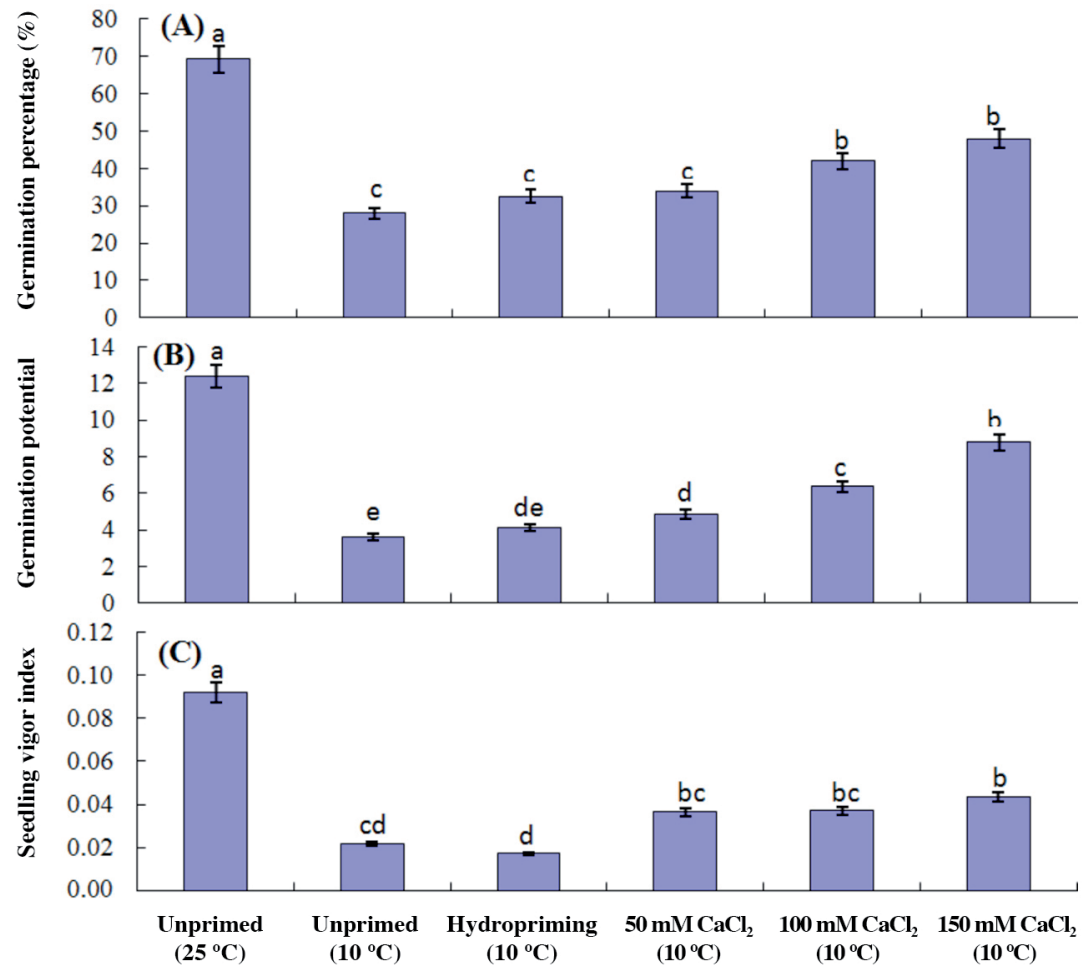

Different letters indicate significant differences among treatments according to Duncan's test $(p<0.05)$. Error bars indicate \pm SE of mean ( $n=3$ ). 
germination traits under chilling stress (Figures 1A-1C). None of the priming treatments reached the same germination traits compared with the optimal condition (Figures 1A-1C). Results further supported the promotive effects of seed priming with $100 \mathrm{mg} \mathrm{L}^{-1} \mathrm{CaCl}_{2}$ on germination and seedling growth of hybrid maize seed sown in plastic pots under optimal and low temperature conditions (Farooq et al., 2008a). Osmopriming with $-1.25 \mathrm{MPa} \mathrm{CaCl}_{2}$ solutions improved the performance of late sown wheat on a farm (Farooq et al., 2008b).

\section{Seed priming triggered antioxidant enzyme activity and decreased malondialdehyde (MDA) content} under chilling stress

Plant exposure to chilling stress usually results in the overproduction of reactive oxygen species (ROS) (Farooq et al., 2008a). If these ROS are not sufficiently scavenged, they can attack important cellular components such as DNA, proteins, lipids, and pigments (Farooq et al., 2008a). The lipid peroxidation reactions could disrupt the lipid bilayers of cell membranes and promote solute leakage and cause adverse effects on seed germination and seedling growth (Farooq et al., 2008a). Compared with the optimal condition, MDA content, which is a product of ROS-induced lipid peroxidation, in $S$. miltiorrhiza seedlings raised from non-primed seeds significantly increased under chilling stress; furthermore, antioxidant enzyme activity (including CAT, POD, and SOD) increased (Figures 2A-2D). These results suggest that chilling stress intensified lipid peroxidation of biomembranes, and this concurs with Farooq et al. (2008a).

As a second messenger in the plant, $\mathrm{Ca}^{2+}$ might activate antioxidant enzymes (such as SOD, POD, and CAT) under temperature stress, which helps plants to lessen damage from ROS-induced oxidation (Farooq et al., 2009). Under chilling stress, osmopriming with 100 and $150 \mathrm{mM} \mathrm{CaCl}_{2}$ significantly increased CAT activity in $S$. miltiorrhiza seedlings, whereas hydropriming (priming with water) and osmopriming with $50 \mathrm{mM} \mathrm{CaCl}_{2}$ did not (Figure 2A). Osmopriming with 50, 100,

Figure 2. Influence of $\mathrm{CaCl}_{2}$ priming on the activities of catalase (CAT) (A), peroxidase (POD) (B), superoxide dismutase (SOD) (C), and malondialdehyde (MDA) content (D) in Salvia miltiorrhiza seedlings under chilling stress.

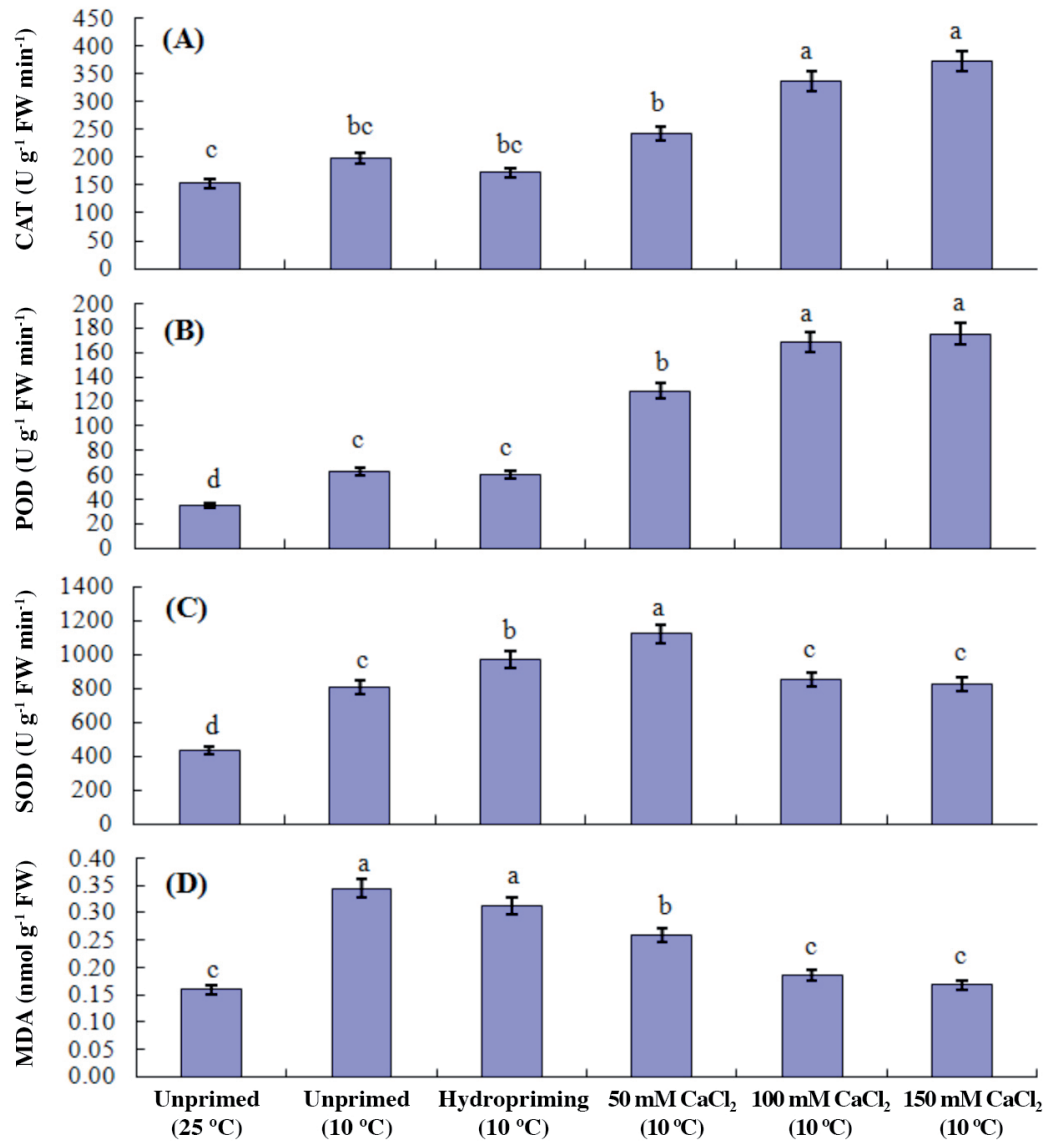

Different letters indicate significant differences among treatments according to Duncan test $(p<0.05)$. Error bars indicate $\pm \operatorname{SE}$ of mean $(\mathrm{n}=3)$. 
and $150 \mathrm{mM} \mathrm{CaCl}_{2}$ significantly increased POD activity in S. miltiorrhiza seedlings, but hydropriming did not (Figure 2B). Hydropriming and osmopriming with $50 \mathrm{mM} \mathrm{CaCl}_{2}$ significantly increased SOD activity (Figure 2C) and $\mathrm{CaCl}_{2}$ priming $(50,100$, and $150 \mathrm{mM})$ significantly decreased MDA content in seedlings (Figure 2D).

The S. miltiorrhiza seedlings from primed seeds had remarkably higher CAT, POD, and SOD activity and lower MDA content than seedlings grown from unprimed seeds. After priming with $\mathrm{CaCl}_{2}, S$. miltiorrhiza seedlings enhanced their ability to remove ROS by strengthening antioxidant enzyme activity, thus providing resistance to chilling stress. Hydropriming cannot decrease the MDA content in the S. miltiorrhiza seedling grown from primed seeds under chilling stress; however, $\mathrm{CaCl}_{2}$ priming reduced MDA content in $S$. miltiorrhiza seedlings grown from primed seeds under chilling stress. Results concur with a previous study by Farooq et al. (2017), who also found that seed priming increases antioxidant enzyme activity in stressed seedlings and that there is a negative relationship between antioxidant enzyme activity and MDA content.

\section{Seed priming increased osmoregulation substances under chilling stress}

Chilling stress reduces root hydraulic conductivity, thus reducing leaf water status and nutrient uptake (Farooq et al., 2009; Yadav, 2010). To counteract osmotic stress, plants accumulate osmoprotectants such as proline, sugars, and amino acids to maintain the water balance (Azooz, 2009).

Many plants accumulate proline when they are subjected to stress conditions such as drought, salinity, and chilling stress (Azooz, 2009). Farooq et al. (2017) indicated that stress tolerance in plants is closely associated with proline accumulation. In addition to acting as an osmoprotectant, proline also plays an important role in maintaining protein stabilization, preventing heat denaturation of enzymes and scavenging free radicals (Matysik et al., 2002). The proline content in $S$. miltiorrhiza seedlings grown from non-primed seeds significantly increased under chilling stress and all priming treatments increased proline content in seedlings from primed seeds (Figure 3C); this concurs with Farooq et al. (2017).

Figure 3. Influence of $\mathrm{CaCl}_{2}$ priming on soluble sugars (A), soluble protein (B), and proline content (C) in Salvia miltiorrhiza seedlings under chilling stress.
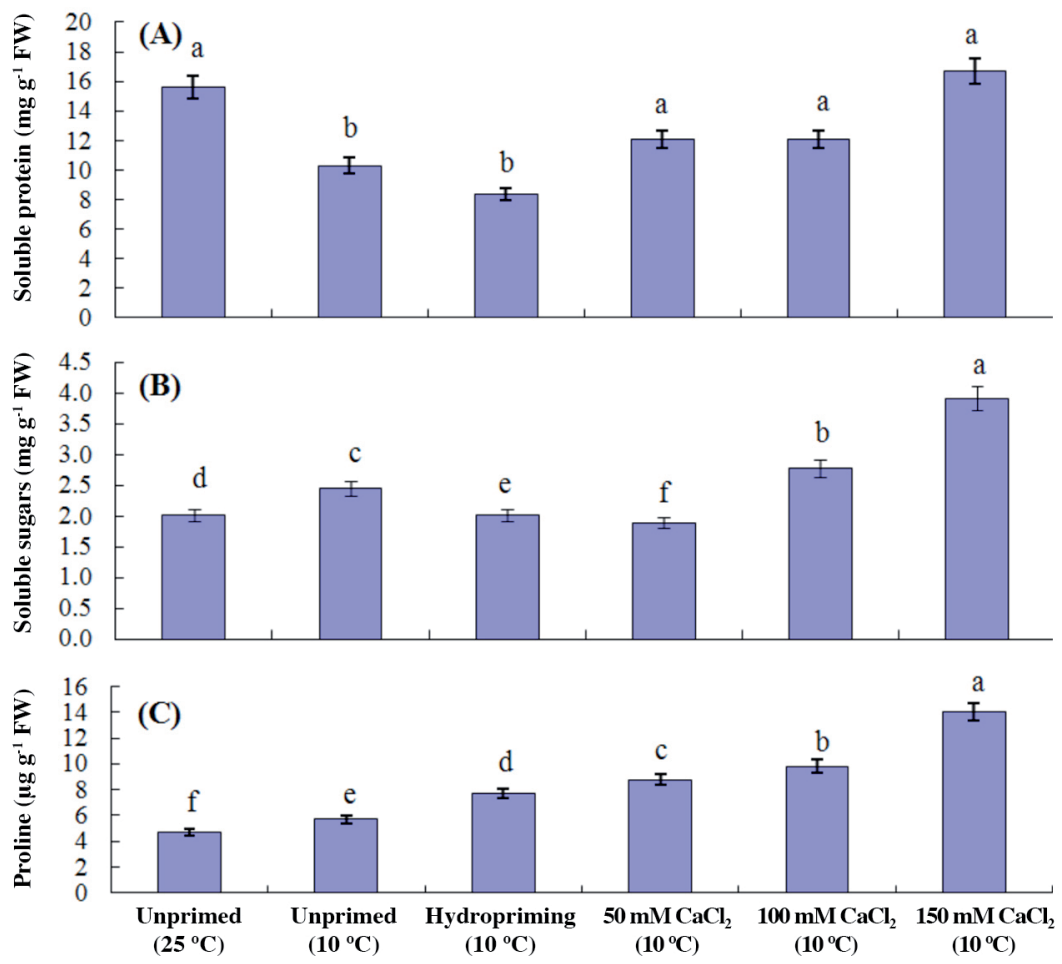

Different letters indicate significant differences among treatments according to Duncan's test $(p<0.05)$. Error bars indicate \pm SE of mean ( $\mathrm{n}=3$ ). 
It has been suggested that soluble sugars play a crucial role in the osmotic adjustment of cells during germination, and that sugar accumulation could maintain normal photophosphorylation under low temperatures (He, 1995). Additionally, sugars are related to the expression of $\alpha$-amylase genes during germination and important $\mathrm{C}$ sources for early seedling growth (Yu et al., 1996). Allen and Ort (2001) indicated that sugars increase in plants under chilling stress. Chilling stress significantly increased soluble sugars in S. miltiorrhiza seedlings (Figure 3B), which concurs with Allen and Ort (2001). The $\mathrm{CaCl}_{2}$ priming significantly increased soluble sugars in $S$. miltiorrhiza seedlings grown from primed seeds under chilling stress (Figure 3B), which agrees with a previous result by You et al. (2002) for wheat in which Ca priming significantly increased photosynthetic pigment content under chilling stress, thus resulting in enhanced photosynthesis.

Soluble proteins are involved in coping with stress conditions by synthesis of transcription factors and stress proteins (Wahid et al., 2007). Protein content in S. miltiorrhiza seedlings grown from non-primed seeds significantly decreased under chilling stress (Figure 3A). Osmopriming with 50, 100, and $150 \mathrm{mM} \mathrm{CaCl}_{2}$ significantly increased soluble protein content in S. miltiorrhiza seedlings under chilling stress, but hydropriming did not (Figure 3A). Ashraf and Foolad (2007) attributed the notable accumulation of protein in tolerant genotypes under water stress to simultaneous protein synthesis.

\section{Seed priming increased photosynthetic pigment content under chilling stress}

Results indicated that total chlorophyll, chlorophyll $a$, and chlorophyll $b$ contents decreased in S. miltiorrhiza seedlings from untreated seeds compared with the optimal control, whereas the xanthophyll content significantly increased under chilling stress (Figures 4A-4D). Under chilling stress, the photosynthetic pigment content decreased in S. miltiorrhiza seedlings grown from unprimed seeds; this agrees with previous results for wheat. The decrease in chlorophyll content might be attributed to the increased degradation of chlorophyll pigments (Ashraf and Foolad, 2007) and the disturbance of chlorophyll pigment synthesis (Zhou et al., 2007) due to enhanced chlorophyllase activity (Turan and Ekmekci, 2011).

Figure 4. Influence of $\mathrm{CaCl}_{2}$ priming on total chlorophyll (A), chlorophyll $a(\mathrm{~B})$, chlorophyll $b(\mathrm{C})$, and carotenoids (D) in Salvia miltiorrhiza leaves under chilling stress.
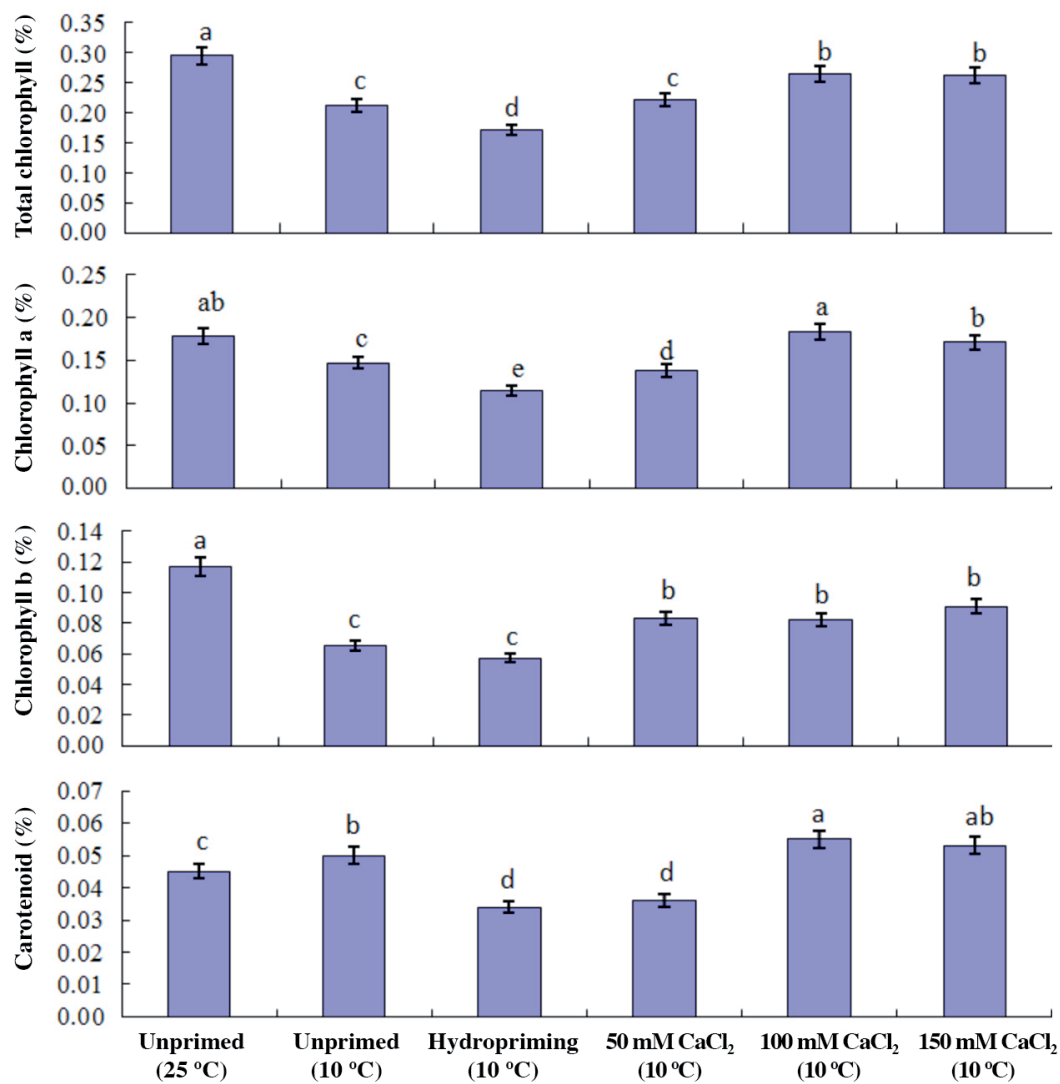

Different letters indicate significant differences among treatments according to Duncan's test $(p<0.05)$. Error bars indicate \pm SE of mean $(n=3)$. 
The application of $\mathrm{Ca}^{2+}$ enhances total chlorophyll and carotenoids; this could be attributed to strengthened antioxidant enzyme activity, which scavenges ROS that can destroy chlorophyll pigments (Yadav, 2010). Under chilling stress conditions, osmopriming with 100 and $150 \mathrm{mM} \mathrm{CaCl}_{2}$ increased total chlorophyll and chlorophyll $a$ (Figures 4A, 4B), osmopriming with 50,100, and $150 \mathrm{mM} \mathrm{CaCl}_{2}$ increased chlorophyll $b$ content (Figure 4C), and osmopriming with $100 \mathrm{mM} \mathrm{CaCl}_{2}$ increased carotenoid content (Figure 4D). Results coincide with a previous study of maize seedlings (Kaczmarek et al., 2017).

\section{CONCLUSIONS}

Priming with $150 \mathrm{mM} \mathrm{CaCl}_{2}$ could significantly improve chilling tolerance of Salvia miltiorrhiza, which was associated with enhanced antioxidant enzymes, increased osmoregulation substances, and lower lipid peroxidation.

\section{REFERENCES}

Aebi, H. 1974. Catalase. p. 673-677. In Bergmeyer, H.U. (ed.) Methods of enzymatic analysis. Academic Press, New York, USA.

Afzal, I., Hussain, B., Basra, S.M.A., and Rehman, H. 2012. Priming with MLE reduces imbibitional chilling injury in spring maize. Seed Science and Technology 40:271-276.

Allen, D.J., and Ort, D.R. 2001. Impact of chilling temperatures on photosynthesis in warm climate plants. Trends in Plant Science 6:36-42.

Ashraf, M., and Foolad, M.R. 2007. Roles of glycine betaine and proline in improving plant abiotic stress resistance. Environmental and Experimental Botany 59:206-216.

Azooz, M.M. 2009. Hibiscus sabdariffa L. (deep red sepals variety) to salinity stress. Journal of Biological Science 9:109-118.

Bates, L.E., Waldren, R.P., and Teare, I.D. 1973. Rapid determination of free proline for water stress studies. Plant and Soil 39:205-207.

Bewley, J.D., Bradford, K.J., Hilhorst, H.W.M., and Nonogaki, H. 2013. Seeds: Physiology of development, germination and dormancy. Springer, New York, USA.

Bradford, M.M. 1976. A rapid and sensitive method for the quantitation of microgram quantities of protein utilizing the principle of protein-dye binding. Analytical Biochemistry 72:248-254.

Chance, B., and Maehly, C. 1955. Assay of catalase and peroxidases. Methods in Enzymology 11:764-775.

Chen, H., Wu, H.X, Yan, B., Zhao, H.G., Liu, F.H., Zhang, H.H., et al. 2018. Core microbiome of medicinal plant Salvia miltiorrhiza seed: A rich reservoir of beneficial microbes for secondary metabolism? International Journal of Molecular Sciences 19(3):672.

Dhindsa, R.S., Dhindsa, P.P., and Thorpe, T.A. 1981. Leaf senescence: correlated with increased levels of membrane permeability and lipid-peroxidation and decreased levels of superoxide dismutase and catalase. Journal of Experimental Botany 32:93-101.

Dodd, A.N., Kudla, J., and Sanders, D. 2010. The language of calcium signaling. Annual Review of Plant Biology 61:593-620.

Farooq, M., Aziz, T., Basra, S.M.A., Wahid, A., Khaliq, A., and Cheema, M.A. 2008a. Exploring the role of calcium to improve chilling tolerance in hybrid maize. Journal of Agronomy and Crop Science 194:350-359.

Farooq, M., Aziz, T., Wahid, A., Lee, D.J., and Siddique, K.H.M. 2009. Chilling tolerance in maize: agronomic and physiological applications. Crop and Pasture Science 60:501-516.

Farooq, M., Basra, S.M.A., Rehman, H., and Saleem, B.A. 2008b. Seed priming enhances the performance of late sown wheat (Triticum aestivum L.) by improving chilling tolerance. Journal of Agronomy and Crop Science 94:55-60.

Farooq, M., Hussain, M., Nawaz, A., Lee, D.J., Alghamdi, S.S., and Siddique, K.H.M. 2017. Seed priming improves chilling tolerance in chickpea by modulating germination metabolism, trehalose accumulation, and carbon assimilation. Plant Physiology and Biochemistry 111:274-283.

He, R.Y. 1995. Plant physical response to low temperature stress. p. 107-141. China Agriculture Press, Beijing, China.

He, G.Q., Xue, R.G., Guo, C.G., Li, G.Q., Zhao, J., and Tan J.J. 2014. Study on seed germination characteristics of Salvia miltiorrhiza Bunge. Seed 33:82-85 (In Chinese).

Heath, R.L., and Packer, I. 1968. Photoperoxidation in isolated chloroplasts. I. Kinetics and stoichiometry of fatty acid peroxidation. Archives of Biochemistry and Biophysics 125:189-198.

Hu, B., Wang, S.S., and Du, Q. 2015. Traditional Chinese medicine for prevention and treatment of hepatocarcinoma: From bench to bedside. World Journal of Hepatology 7:1209-1232.

Irigoyen, J.J., Emerich, D.W., and Sanchez-Diaz, M. 1992. Water stress induced changes in concentrations of proline and total soluble sugars in nodulated alfalfa (Medicago sativa) plants. Physiologia Plantarum 84:55-60. 
Kaczmarek, M., Fedorowicz-Stronska, O., Glowacka, K., Waskiewicz, A., and Sadowski, J. 2017. CaCl $_{2}$ treatment improves drought stress tolerance in barley (Hordeum vulgare L.) Acta Physiologiae Plantarum 39:41. doi.org/10.1007/s11738-016-2336-y.

Li, Z., Xu, J., Gao, Y., Wang, C., Guo, G., Luo, Y., et al. 2017. The synergistic priming effect of exogenous salicylic acid and $\mathrm{H}_{2} \mathrm{O}_{2}$ on chilling tolerance enhancement during maize (Zea mays L.) seed germination. Frontiers in Plant Science 8:1153. doi:10.3389/fpls.2017.01153.

Lichtenthaler, H.K. 1987. Chlorophylls and carotenoids: pigments of photosynthetic biomembranes. Method in Enzymology 148:350-382.

Matysik, J., Alia, Bhalu, B., and Mohanty, P. 2002. Molecular mechanisms of quenching of reactive oxygen species by proline under stress in plant. Current Science 82:525-532.

Paparella, S., Araújo, S.S., Rossi, G., Wijayasinghe, M., Carbonera, D., and Balestrazzi, A. 2015. Seed priming: state of the art and new perspectives. Plant Cell Reports 34:1281-1293.

Sebastiani, L., Lindberg, S., and Vitagliano, C. 1999. Cytoplasmic free $\mathrm{Ca}^{2+}$ dynamics in single tomato (Lycopersicon esculentum) protoplasts subjected to chilling temperatures. Physiologia Plantarum 105:239-245.

Tang, R.J, and Luan, S. 2017. Regulation of calcium and magnesium homeostasis in plants: from transporters to signaling network. Current Opinion in Plant Biology 39:97-105.

Turan, O., and Ekmekci, Y. 2011. Activities of photosystem II and antioxidant enzymes in chickpea (Cicer arietinum L.) cultivars exposed to chilling temperatures. Acta Physiologiae Plantarum 33:67-78.

Wahid, A., Gelani, S., Ashraf, M., and Foolad, M.R. 2007. Heat tolerance in plants: an overview. Environmental and Experimental Botany 61:199-223.

Yadav, S.K. 2010. Cold stress tolerance mechanisms in plants. A review. Agronomy for Sustainable Development 30:515-527.

Yan, M. 2015. Seed priming stimulate germination and early seedling growth of Chinese cabbage under drought stress. South African Journal of Botany 99:88-91.

You, J.H., Lu, J.M., and Yang, W.J. 2002. Effects of $\mathrm{Ca}^{2+}$ on photosynthesis and related physiological indexes of wheat seedlings under low temperature stress. Acta Agronomica Sinica 28:693-696.

Yu, S.M., Lee, Y.C., Fang, S.C., Chan, M.T., Hwa, S.F., and Liu, L.F. 1996. Sugars act as signal molecules and osmotica to regulate the expression of $\alpha$-amylase genes and metabolic activities in germinating cereal grains. Plant Molecular Biology 30:1277-1289.

Zhou, Y., Huang, L., Zhang, Y., Shi, K., Yu, J., and Nogués, S. 2007. Chill-induced decrease in capacity of RuBP carboxylation and associated $\mathrm{H}_{2} \mathrm{O}_{2}$ accumulation in cucumber leaves are alleviated by grafting onto figleaf gourd. Annals of Botany 100:839-848. 